\title{
KEBERTERIMAAN INSTRUMEN PENILAI KOMPETENSI KOMUNIKASI DAN INTERAKSI POSITIF KONSELOR TERHADAP MASYARAKAT SEKOLAH
}

\author{
Setya Adi Sancaya ${ }^{1}$, Yuanita Dwi Krisphianti ${ }^{2}$, Guruh Sukma Hanggara ${ }^{3}$, M. Fauzan Muzaki ${ }^{4}$ \\ Universitas Nusantara PGRI Kediri ${ }^{1,2,3,4}$ \\ Email: sadisancaya@gmail.com¹, ju.wahyu@gmail.com², kangguruh@gmail.com³
}

\begin{abstract}
An important competency that must be possessed by the counselor is competence in communication and positive interaction with the school society. These skills include three things, namely with teaching staff, students, and students. From the dispute, there were no instruments that were eligible to get this ranking. The purpose of this research is to create a communication instrument of communication and positive interaction with the school society that has acceptance by experts and understanding. This research method is development research. Research subjects were two experts from academia and two experts from guidance and counseling. The results of the study with the subject of two academic experts are 0.34 with quite good/decent enough criteria. Results from research with expert research subjects 0.36 with the criteria quite good/decent enough. The conclusion from this study shows that the assessment instrument of communication competence and positive counselor interaction with the school society has had a good acceptance from experts and conversions. From the findings, the researcher provides suggestions: 1) before applying the instrument, the researcher needs to provide an understanding in the form of a direct explanation to the BK teacher on the function of the BK performance evaluation instrument; 2) the researcher should develop instruments using easy to understand language, straightforward and simple sentences, and the sentence is not too long; 3 ) in further research it is necessary to further develop the results of this research in the form of applicable technology.
\end{abstract}

Keywords assessment instruments, counselor competencies, communication, positive interactions, school community

\begin{abstract}
ABSTRAK
Kompetensi penting yang harus dimiliki oleh konselor adalah terampil dalam komunikasi dan interaksi positif dengan komunitas sekolah. Keterampilan ini mencakup tiga hal, yakni dengan staf pendidik, peserta didik, dan orangtua peserta didik. Dari penelisuran belum ditemukan instrumen yang layak untuk menilai ketiga hal tersebut. Tujuan penelitian adalah menghasilkan instrumen penilai kompetensi komunikasi dan interaksi positif konselor terhadap masyarakat sekolah yang memiliki keberterimaan oleh ahli dan praktisi. Metode penelitian ini adalah developmental research. Subjek penelitian adalah dua ahli dari akademisi dan dua ahli dari praktisi bimbingan dan konseling. Hasil dari penelitian dengan subjek dua ahli akademisi adalah 0.34 dengan kriteria cukup baik/ cukup layak. Hasil dari penelitian dengan subjek dua ahli praktisi adalah 0.36 dengan kriteria cukup baik/ cukup layak. Kesimpulan dari penelitian ini menunjukkan bahwa instrumen penilai kompetensi berkomunikasi dan interaksi positif konselor terhadap masyarakat sekolah telah memiliki keberterimaan baik dari ahli dan praktisi. Dari temuan, peneliti memberikan saran: 1) sebelum menerapkan instrumen, peneliti perlu memberikan pemahaman berupa penjelasan langsung terhadap guru BK akan fungsi dari instrumen evaluasi kinerja $\mathrm{BK}$; 2) peneliti hendaknya dalam pengembangan instrumen menggunakan bahasa yang mudah dipahami, kalimat yang lugas dan
\end{abstract}

\section{Kata Kunci} instrumen penilai, kompetensi konselor, komunikasi, interaksi positif, masyarakat sekolah 
sederhana, dan kalimat tidak terlalu panjang; 3 ) dalam penelitian selanjutnya perlu mengebangkan lebih lanjut hasil pengembangan dari penelitian ini dalam bentuk teknologi yang aplikatif.

Cara mengutip: Sancaya, S. A., Krisphianti, Y. D., Hanggara, G. S., \& Muzaki, M. F. (2020). Keberterimaan Instrumen Penilai Kompetensi Komunikasi dan Interaksi Positif Konselor Terhadap Masyarakat Sekolah. Nusantara of Research : Jurnal Hasil-Hasil Penelitian Universitas Nusantara PGRI Kediri (eJournal), 6(2), 105-114. https://doi.org/10.29407/nor.v6i2.13603

\section{PENDAHULUAN}

Bimbingan dan konseling (BK) merupakan salah satu bagian dari system pendidikan di sekolah yang tidak terpisahkan. Program layanan bimbingan dan konseling disusun bertujuan untuk memfasilitasi peserta didik mencapai perubahan positif yang memungkinkan siswa menuju kemandirian hidup (Gysbers \& Henderson, 2006). Agar tercapai tujuan tersebut, maka dibutuhkan pelayanan yang optimal dan sekaligus keprofesionalan guru BK/ konselor. Keoptimalan dalam pelaksanaan layanan Bimbingan dan Konseling sekolah yang komprehensif menurut Sink (2009) dapat dilihat dari hasil evaluasi pada empat komponen yaitu: audit program, penilaian berbasis hasil, penilaian kebutuhan dan tinjauan personel. Dalam tinjauan personel yang dimaksud adalah berkaitan dengan kompetensi konselor.

Kompetensi konselor merupakan hal yang penting juga untuk dievaluasi. Dengan kompetensi yang memadahi maka konselor dapat merancang layanan BK yang dibutuhkan oleh siswa dan melayani siswa dengan menyenangkan, bermakna dan efektif. Salah satu kompetensi konselor yang berpengaruh dalam pelaksanaan program bimbingan dan konseling di sekolah adalah kemampuan dalam berkomunikasi dan berinteraksi positif dengan masyarakat sekolah (Gysbers \& Handersons: 2012). Kemampuan ini meliputi tiga hal yakni, berkomunikasi dan berinteraksi positif dengan peserta didik, staf pendidik lainya, dan orang tua/ tokoh masyarakat (Missouri Departement of elementary and secondary education, 2000; Gysbers \& Henderson, 2006; Coleman \& Yeh, 2008).

Kompetensi dalam berkomunikasi merupakan hal yang esensial dalam membangun rasa hormat antara konselor dan konseli (Schmith: 2008). Adanya rasa hormat dan perasaan saling menghormati, maka hubungan relasional konselor dan siswa akan lebih interaktif dan produktif dalam mengantarkannya mencapai kematangan optimal. Dan menurut Hanggara \& Setyaputri (2017) kompetensi sosial ini merupakan salah satu faktor penting terciptanya kemenarikan interpersonal konselor yang dapat membangkitkan dan meningkatkan motivasi siswa dalam mengikuti bimbingan kelompok sebagai salah satu layanan dalam bimbingan dan konseling. Untuk itu kompetensi konselor dalam berkomunikasi dengan siswanya akan menambah keefektifan pemberian layanan BK di sekolah.

Berkomunikasi dan berinteraksi tidak hanya konselor lakukan dengan siswa saja tetapi juga dengan staf pendidik lainya. Interaksi dan kolaborasi dengan staf pendidik lainya sangatlah disarankan dalam penyelenggaraan BK komprehensif di sekolah (Gysbers \& Handersons: 2012) sehingga tujuan pendidikan secara umum akan lebih dapat tercapai. Selanjutnya adalah komuikasi dan interaksi positif dengan orang tua siswa yang memungkinkan konselor bertukar informasi tentang perkembangan siswa. Interaksi dengan orang tua haruslah 
dapat terselenggara dengan baik dan efektif mengingat elemen ini merupakan sumber informasi utama bagi perkembangan siswa diluar sekolah dan skaligus kesempatan untuk berkomunikasi dan berinteraksi dengan mereka begitu terbatas.

Kompetensi berkomunikasi dan berinteraksi pada konselor senantiasa harus diukur dan ditingkatkan, mengingat begitu penting posisinya dalam menopang penyelenggaraan layanan BK yang diselenggarakan. Menurut Astramovich \& Coker (2007) pertanggungjawaban dan gerakan reformasi pendidikan dan profesi layanan manusia telah menekan konselor untuk menunjukan hasil dari program dan layanan konseling. Untuk memastikan dan mengukur hasil kompetensi/ kinerja dan juga kemampuan konselor maka dibutuhkanlah kegiatan evaluasi. Hal ini sesuai dengan penelitian Hidayanti, dkk (2017) dimana evaluasi semakin menjadi hal yang penting untuk menunjukan bahwa konselor sekolah telah bekerja maksimal memberikan kontribusi bagi keberhasilan siswa terutama prestasi akademik. Evaluasi bagi guru BK merupakan inti penyempurnaan profesionalitas guru BK. Evaluasi merupakan suatu proses dengan cara mengumpulkan data atas apa yang sudah dilakukan secara objektif berdasarkan analisis yang sistematis dan jelas. Dengan demikian evaluasi pada kinerja guru BK khususnya kompetensi komunikasi dan interaksi positif penting dilakukan.

Pelaksanaan evaluasi kinerja guru BK dibutuhkan suatu instrumen yang valid. Kenyataannya di lapang belum banyak instrumen valid yang dapat digunakan untuk evaluasi tersebut. Hal ini sesuai dengan penelitian yang telah dilakukan oleh Juniarti, dkk (2017), evaluasi pelaksanaan program bimbingan dan konseling belum terlaksana secara maksimal, karena tidak mempunyai waktu yang cukup untuk melakukan evaluasi dan belum tersedianya alat instrumen evaluasi yang valid, reliable, dan objektif. Selanjutnya hal serupa juga ditemukan dalam penelitian Febriyani \& Triyono (2018) yang mengidentifikasi bahwa 31,1\% guru BK SMA Negeri di kota padang mengalami hambatan internal dalam melaksanakan evaluasi program dan $28,4 \%$ mengalami hambatan secara eksternal. Dengan demikian, secara umum dapat dikatakan jika pelaksanaan evaluasi yang dilakukan oleh guru BK belum optimal. Lebih khusus, dari studi literatur dan penelusuran peneliti belum ditemukan instrument evaluasi diri bagi guru BK yang khusus menilai kinerja komunikasi dan interaksi positif dengan masyarakat sekolah.

Berdasarkan paparan di atas, maka dirasa penting untuk menyusun sebuah instrumen evaluasi kinerja guru BK dalam berkomunikas dan berinteraksi positif dengan masyarakat sekolah. Oleh karena itu, tujuan penelitian ini diharapkan menghasilkan instrumen penilai kompetensi komunikasi dan interaksi positif konselor terhadap masyarakat sekolah yang memiliki keberterimaan oleh ahli dan praktisi.

\section{METODE}

Pada penelitian ini digunakan teknik developmental research yang lebih khusus pada pengembangan instrumen. Model pengembangan yang digunakan menggunakan rujukan dari Gregory (2014). Model ini dilaksanakan dalam enam langkah, yakni a) mendefinisikan tes, b) memilih metode penskalaan, c) menkonstruk item, d) menguji item, e) merevisi tes, dan f) mempublish tes sebagaimana pada gambar 1 berikut ini. 


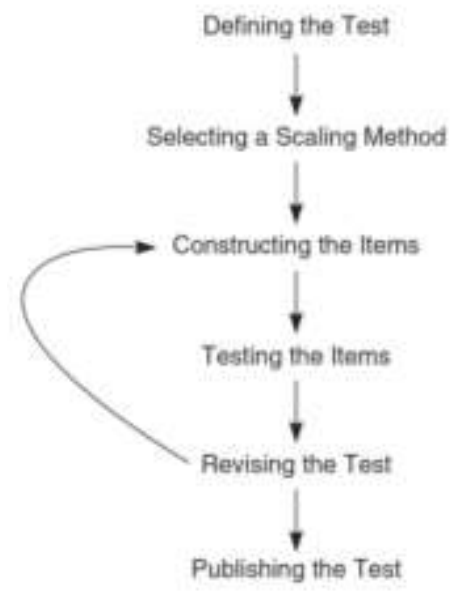

Gambar 1. Proses Penyusunan Instrumen

Sumber: Gregory, 2014

Dalam uji keberterimaan, peneliti meminta dua orang dosen BK UNP Kediri diluar peneliti sebagai penguji dan dianggap kompeten dan satu orang praktisi yaitu konselor di SMAN 1 Sampung-Ponorogo serta satu orang praktisi yaitu konselor di SMKN 1 Trenggalek. Dalam proses pengumpulan data menggunakan skala keberterimaan. Penilaian keberterimaan meliputi aspek kegunaan, kelayakan, ketepatan, dan kepatutan instrumen (Stufflebeam, 2014). Dalam setiap pernyataan pada skala memiliki gradasi berupa skala 1-4, yang bermakna $1=$ tidak jelas/ tidak tepat/ tidak praktis/ tidak relevan/ tidak perlu/ tidak berfaedah/tidak penting; 2= kurang jelas/ kurang tepat/ kurang praktis/ kurang relevan/ kurang perlu/ kurang faedah/ kurang penting; $3=$ jelas/ tepat/ praktis/ relevan/ berfaedah/ penting; dan 4= sangat jelas/ sangat tepat/ sangat praktis/ sangat relevan/ sangat berfaedah/ sangat penting (Hanggara, Andrianie \& Ariyanto, 2018). Skala akseptabilitas yang digunakan terdiri dari 2 skala yakni skala akseptabilitas untuk ahli akademisi BK dan skala akseptabilitas untuk praktisi BK. Skala ini selain mengakumulasi informasi secara numerik juga dilengkapi dengan kolom komentar yang memberikan ruang para ahli untuk memberikan saran dan informasi kualitatif yang berguna untuk perbaikan instrumen yang dihasilkan.

Selanjutnya ditetapkan tiga kriteria untuk interpretasi hasil penilaian ahli, yaitu; 1) rentang 0,66-1,00 dengan kriteria baik/ layak; 2) rentang nilai 0,33-0,65 dengan kriteria cukup baik/ cukup layak; 3) rentang nilai 0,00-0,32 dengan kriteria tidak baik/ tidak layak. Pengujian yang melibatkan dua uji ahli yang berbeda, menjadikan peneliti memilih menggunakan tabulasi kesepakatan penilai (inter-rater agreement), Adapun format gambar dapat dilihat pada gambar 1. Dari model (inter-rater agreement), pada gambar 1, maka didapat ketentuan indeks uji ahli dengan menggunakan rumus pada gambar 2 .

Pada gambar 1 dan 2 terdapat penggunaan A, B, C, D. Adapun keterangan dari penggunaan tersebut adalah; A menunjukkan relevansi rendah dari ahli 1 dan ahli 2; B menunjukkan relevansi tinggi dari ahli 1 dan relevansi rendah dari ahli 2; C menunjukkan relevansi rendah dari ahli 1 dan relevansi tinggi dari ahli 2; D menunjukkan relevansi tinggi dari ahli 1 dan ahli 2. 


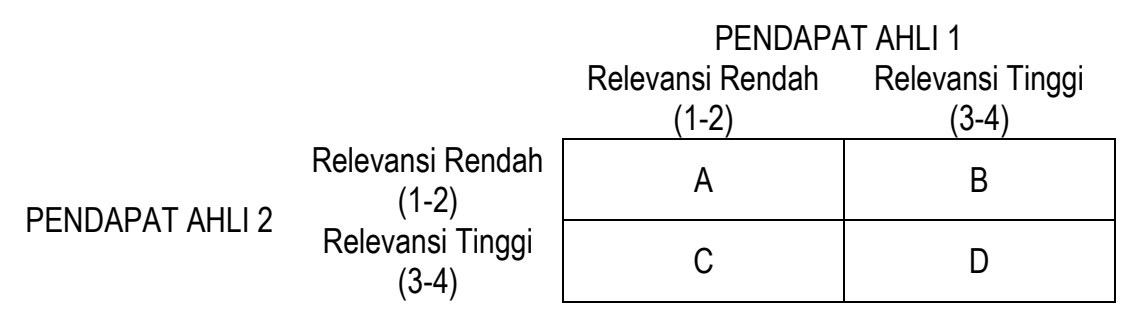

\section{Gambar 2. Inter-rater Agreement Model Sumber: Gregory, 2014}

$$
\text { Indeks Uji Ahli }=\frac{D}{(A+B+C+D)}
$$

Gambar 3. Indeks uji ahli

HASIL Sumber: Gregory, 2014

Penelitian pengembangan ini menghasilkan sebuah instrumen penilai kompetensi komunikasi dan interaksi positif konselor terhadap masyarakat sekolah yang memiliki keberterimaan oleh ahli dan praktisi. Adapun yang dimaksud dengan berkomunikasi dan interaksi positif dengan masyarakat sekolah adalah, guru BK mampu menjalin hubungan dan komunikasi baik dalam melaksanakan tugas-tugas dengan peserta didik, staf pendidik, dan orangtua peserta didik. Instrumen kinerja konselor yang dihasilkan dalam penelitian ini terdiri dari 60 item dengan 3 sub bagian yaitu komunikasi/ interaksi dengan siswa, komunikasi/ interaksi dengan staf pendidik lainya serta komunikasi/ interaksi dengan orang tua/ tokoh masyarakat. Dari instrumen yang dikembangkan lalu diujikan pada 2 orang ahli dan 2 orang praktisi untuk mengetahuai keberterimaannya. Penguji keberterimaan instrumen ini, dari ahli akademisi dilakukan oleh dua orang dosen pengajar program studi bimbingan dan konseling UN-PGRI Kediri diluar tim pengembang instrumen ini, yang telah berpengalaman selama 5 tahun sebagai dosen. Sedangkan dari ahli praktisi, peneliti mengujikan pada konselor yang telah memiliki pengalaman 5-10 tahun sebagai konselor dari jenjang pendidikan yang sama tetapi dari dua rumpun sekolah yang berbeda yaitu konselor SMA dan konselor SMK sehingga cakupanya lebih luas. Adapaun hasil yang didapat dalam uji keberterimaan ahli dan praktisi ini adalah sebagai berikut:

Tabel. 1 Hasil Uji keberterimaan ahli akademisi dan praktisi

\begin{tabular}{lll}
\hline \multicolumn{1}{c}{ Penguji } & \multicolumn{1}{c}{ Hasil } & \multicolumn{1}{c}{ Interpretasi } \\
\hline Ahli akademisi & Hasil perhitungan dari uji ahli akademisi & Dari hasil analisis penilaian, instrumen ini \\
BK & BK menunjukkan hasil 0,34. Hal ini & dikatakan cukup layak. Akan tetapi, peneliti \\
& memiliki arti bahwa instrumen cukup & tetaplah harus memperhatikan masukan \\
& baik/ cukup layak. & dari ahli akademisi yakni tentang beberapa \\
& Adapun saran yang diberikan adalah a) & kalimat dari item pernyataan yang memiliki \\
& kalimat dalam item harus lugas, tidak & makna ambigu dengan panjangnya kalimat. \\
& terlalu panjang, karena ada beberapa & Selain itu, ada item yang menggunakan \\
& item yang lugas dan cukup panjang; b) & bahasa yang sulit untuk dipahami sehingga \\
& ada beberapa kata yang hilang dan ada & mengakibatkan instrumen sulit untuk dibaca. \\
& kata asing yang perlu dicermati & Hal ini akan menjadi masukan dan \\
\hline
\end{tabular}




\begin{tabular}{|c|c|c|}
\hline & $\begin{array}{l}\text { penulisannya; c) akan lebih baik jika } \\
\text { diberikan tambahan keterangan } \\
\text { mengenai lama waktu pengerjaan pada } \\
\text { petunjuk pengisian, dan d) pada } \\
\text { beberapa item penggunaan bahasa lebih } \\
\text { baik disederhanakan susunannya } \\
\text { dengan tidak mengurangi makna. }\end{array}$ & $\begin{array}{l}\text { pertimbangan peneliti dalam melakukan } \\
\text { pengembangan instrumen evaluasi konselor } \\
\text { ke depannya. }\end{array}$ \\
\hline Ahli praktisi BK & $\begin{array}{l}\text { Hasil perhitungan dari uji ahli praktisi BK } \\
\text { menunjukkan hasil 0,36. Hal ini memiliki } \\
\text { arti bahwa instrumen cukup baik/ cukup } \\
\text { layak. } \\
\text { Adapun saran yang diberikan oleh ahli } \\
\text { praktisi adalah sebagai berikut. } \\
\text { a) instrumen yang dibuat sudah bagus; b) } \\
\text { akan lebih baik kalimat item yang } \\
\text { digunakan menggunakan kalimat } \\
\text { langsung; c) akan lebih baik item no 10, } \\
\text { 17, 46, 47, 32, dan } 51 \text { menggunakan } \\
\text { kalimat langsung dengan pola kalimat S- } \\
\text { P-O; d) akan lebih baik jika penggunaan } \\
\text { instrumen dengan memanfaatkan } \\
\text { teknologi yang ada, yakni hasil analisis } \\
\text { dari instrumen ini bisa dicetak langsung } \\
\text { dan diberikan kepada guru BK; e) kalimat } \\
\text { pengantar dan petunjuk pengisian lebih } \\
\text { disederhanakan disesuaikan dengan } \\
\text { pemahaman konselor; f) kekhasan } \\
\text { konselor terletak pada konseling, pada } \\
\text { komunikasi dengan peserta didik perlu } \\
\text { pengkhususan yang menggali tentang } \\
\text { keterampilan komunikasi konselor saat } \\
\text { konseling dengan peserta didik. }\end{array}$ & $\begin{array}{l}\text { Dari hasil analisis penilaian, instrumen } \\
\text { evaluasi ini dikatakan cukup layak karena } \\
\text { praktisi merasa instrumen evaluasi ini } \\
\text { penting digunakan untuk mengukur } \\
\text { keterampilan komunikasi dan interaksi } \\
\text { positif konselor dengan masyarakat sekolah. } \\
\text { Meskipun demikian, ada beberapa masukan } \\
\text { yang harus ditindaklanjuti termasuk susunan } \\
\text { kalimat pada item instrumen yang harus } \\
\text { diperbaiki. Dalam hal ini praktisi menandai } \\
\text { dengan spesifik sehingga menjadikan } \\
\text { peneliti lebih mudah untuk memperbaiki } \\
\text { item-item tersebut. Berdasarkan } \\
\text { pengalaman dan kemajuan yang ada } \\
\text { praktisi juga menyarankan agar instrumen } \\
\text { ini bisa dikembangkan dengan } \\
\text { memanfaatkan teknologi yang ada agar } \\
\text { konselor dapat mengetahui secara langsung } \\
\text { hasil analisis instrumen yang teah } \\
\text { dikerjakan. Lebih lanjut praktisi juga } \\
\text { menyarankan agar komponen komunikasi } \\
\text { dalam konseling juga diperdalam. Dengan } \\
\text { memperhatikan penilaian dan saran praktisi } \\
\text { maka instrumen ini cukup layak dan dirasa } \\
\text { penting untuk digunakan serta potensial } \\
\text { untuk dikembangkan lebih lanjut. }\end{array}$ \\
\hline
\end{tabular}

Berdasarkan hasil uji ahli keberterimaan para ahli dari akademisi dan praktisi menunjukkan kriteria nilai pada rentang 0,33-0,65 dimana memiliki arti cukup baik/cukup layak. Adapun rincian hasil dari dua uji ahli adalah (a) hasil dari dua uji ahli akademisi dengan nilai 0,34 kriteria cukup baik/ cukup layak dan (b) hasil dari dua uji ahli praktisi dengan nilai 0,36 kriteria cukup baik/ cukup layak. Hasil ini menunjukkan bahwa instrumen penilai kompetensi komunikasi dan interaksi positif konselor terhadap masyarakat sekolah yang dihasilkan cukup memenuhi kriteria akseptabilitas/ keberterimaan dari akademisi dan praktisi, sehingga bisa dikatakan instrumen evaluasi ini bisa digunakan untuk mengevaluasi kompetensi/ kinerja konselor dalam berkomunikasi dan interaksi positif dengan masyarakat sekolah.

\section{PEMBAHASAN}

Berdasarkan hasil uji keberterimaan dari para ahli dinyatakan bahwa instrumen evaluasi kompetensi berkomunikasi dan interaksi positif konselor terhadap masyarakat sekolah cukup baik/ cukup layak untuk digunakan sebagai instrumen evaluasi. Instrumen ini penting digunakan dalam pelaksanaan evaluasi kinerja konselor dalam berkomunikasi dan interaksi positif dengan masyarakat sekolah. Keterampilan berkomunikasi dan berinterkasi positif dengan masyarakat sekolah sangat menunjang profesionalitasan konselor di sekolah. Dalam rumusan standard kulaifikasi akademik dan kompetensi konselor (Mendiknas, 2008) ini paling tidak masuk dalam 2 kategori kompetensi yaitu 1) kompetensi sosial khususnya dalam 
mengimplementasikan kolaborasi intern di tempat kerja; 2) kompetensi kepribadian khususnya dalam menghargai dan menjunjung tinggi nilai-nilai kemanusiaan, individualitas dan kebebasan memilih serta dalam menunjukan integritas stabilitas kepribadian yang kuat. Dengan demikian maka dapat dikatakan bahwa kompetensi berkomunikasi dan interaksi positif konselor terhadap masyarakat sekolah penting dan menjadi keharusan untuk dimiliki oleh seorang konselor.

Meskipun demikian, ada beberapa hal yang dapat menjadi perhatian dan pertimbangan agar instrumen ini bisa optimal dan baik digunakan sebagai instrumen evauasi berdasarkan masukan para ahli diatas. Adapun beberapa hal yang menjadi perhatian dan pertimbangan yang diberikan oleh para ahli akademisi dan praktisi adalah 1) penggunaan kalimat item harus lugas dan langsung dengan menggunaka susunan kalimat S-P-O; 2) perlunya keterangan mengenai lama waktu pengerjaan pada petunjuk pengisian; 3) penggunaan kalimat hendaknya lebih sederhana tanpa mengurangi makna; 4) kalimat pengantar dan petunjuk pengisian lebih disederhanakan disesuaikan dengan pemahaman konselor. Masukan-masukan tersebut langsung ditindak-lanjuti dalam revisi instrumen ini.

Sedangkan dua masukan lagi yaitu 1) sebaiknya instrumen ini dikembangkan dengan menggunakan teknologi, agar analisis bisa langsung dilakukan dan langsung dicetak dan 2) kekhasan konselor terletak pada konseling, pada komunikasi dengan peserta didik perlu pengkhususan yang menggali tentang keterampilan komunikasi konselor saat konseling dengan peserta didik. Dianggap sebagai keterbatasan dalam penelitian ini, yang akan ditindaklanjuti oleh peneliti dalam penelitian selanjutnya, mengingat dalam pengembangan 2 aspek tersebut membutuhkan tahapan pengembangan yang relatif berbeda dari pengembangan instrumen yang direncanakan. Disamping itu juga dibutuhkan kajian teori yang mendalam khususnya terkait dengan kekhasan dan kemenarikan dari instrumen evaluasi pelaksanaan konseling, mengingat talah di jumpai beberapa pengembangan yang serupa. Contoh dari instrumen evaluasi kegiatan konseling yang dimaksud seperti yang dikembangkan oleh Barida \& Sutamo (2016) yaitu instrumen evaluasi "Self Evaluation" dan "Peer Evaluation" layanan konseling individu di sekolah bagi konselor. Begitu juga Purwaningrum (2011) juga mengembangkan Instrumen Evaluasi Diri Penguasaan Teknik Dasar Komunikasi dalam Konseling. Dan juga Inventory for Rating Counseling yang dikembangkan oleh (Linden, Stone \& Shertzer, 1965).

Hasil pengembangan dalam penelitian ini sejalan dengan pendapat Hidayanti, dkk (2017) yang menyatakan bahwa evaluasi itu penting ada karena merupakan proses yang menjadi dasar penentuan suatu pengambilan keputusan. Dengan kata lain, apabila menginginkan suatu keputusan yang memiliki dampak positif bagi sekitar maka perlu melakukan evaluasi pada setiap unsur yang menjadikan keputusan itu ada. Unsur itu mulai dari pengambil keputusan, pelaksanaan sebelum adanya keputusan baru, dan dampak dari pelaksanaan sebelum adanya keputusan yang baru. Dimana semua itu merupakan proses dalam evaluasi. Maka dengan kata lain evaluasi kinerja konselor penting dilakukan.

Missouri Departement of elementary and secondary education (2000) evaluasi kinerja guru BK yang perlu dilaksanakan ada enam standar yakni (a) konselor sekolah harus mengimplementasikan kurikulum BK yang efektif digunakan untuk semua siswa, (b) konselor 
sekolah harus mengimplementasikan kurikulum pada siswa dengan bidang pribadi, belajar, dan karir, (c) konselor sekolah harus mengimplementasikan layanan responsif pada individu maupun kelompok dalam layanan konseling, konsultasi maupun referral, (d) konselor sekolah harus mengimplementasikan program yang memiliki support sistem pada setiap program yang dibuat, (e) konselor sekolah menggunakan komunikasi dan interaksi positif dengan masyarakat sekolah, dan (f) konselor sekolah harus memiliki tanggung jawab yang tinggi akan tugas yang dimiliki. Di antara enam standar, berdasarkan observasi awal yang telah dilakukan terdapat satu standar yang mencakup keseluruhan, yakni standar lima dimana konselor sekolah mampu berkomunikasi dan berinteraksi positif dengan masyarakat sekolah. Masyarakat sekolah yang dimaksud adalah staf pendidik, peserta didik, dan orangtua peserta didik.

Standar lima dianggap sebagai kompetensi pokok dari keseluruhan standar yang lain, karena apabila seorang konselor tidak memiliki kemampuan berkomunikasi dan berinteraksi positif dengan masyarakat sekolah, maka akan menimbulkan problematik bagi pelaksanaan BK di sebuah sekolah. Hal ini sejalan dengan (Mendiknas, 2008 dimana didalamnya terdapat empat kompetensi dikatakan bahwa seorang konselor itu profesional, salah satunya adalah kompetensi sosial. Kompetensi sosial memiliki indikator yang terdiri dari; (a) mengimplementasikan kolaborasi intern di tempat kerja, (b) berperan dalam organisasi dan kegiatan profesi bimbingan dan konseling, dan (c) mengimplementasikan kolaborasi antar profesi.

Ketiga indikator dalam kompetensi sosial membutuhkan ketrampilan dari seorang konselor yakni berkomunikasi dan beinteraksi positif dengan masyarakat sekolah. Hal ini menunjukkan bahwa instrumen evaluasi kinerja konselor dalam bekomunikasi dan berinteraksi positif perlu dibuat. Senada dengan pendapat Hidayanti, dkk (2017), evaluasi dianggap sebagai hal penting dalam managemen bimbingan. Penilaian kemampuan konselor/ guru BK akan membantu sejauh mana konselor tersebut mampu melaksanakan layanan BK di sekolah. Pendapat ini dikuatkan pula oleh pendapat Gibson \& Mitchel (2011) bahwa terdapat prinsip yang harus digunakan dalam melaksanakan evaluasi bimbingan dan konseling salah satunya yakni harus menggunakan pengukuran yang sahih. Pengukuran yang dimaksud adalah alat ukur, artinya dibutuhkan alat ukur untuk menilai kemampuan konselor dalam melaksanakan layanan bimbingan dan konseling di sekolah. Evaluasi kinerja konselor dalam berkomunikasi dan interaksi positif perlu dilakukan, hal ini diperkuat oleh penelitian yang dilakukan Sugiyo \& Muslikah (2018), konselor sekolah harus memiliki kemampuan dalam berkomunikasi dan berinteraksi untuk mengambil setiap keputusan yang akurat guna meningkatkan kualitas bimbingan dan konseling yang ada di sekolah.

Instrumen penilai kompetensi komunikasi dan interaksi positif konselor terhadap masyarakat sekolah memerlukan revisi yang akurat dan tepat. Mengingat pentingnya evaluasi kinerja yang harus dilaksanakan pada setiap konselor. Peneliti perlu melakukan revisi terhadap instrumen evaluasi ini berdasarkan masukan dan saran dari para ahli akademisi maupun praktisi BK. 


\section{KESIMPULAN DAN SARAN}

Dari hasil inter rater agreement model yang telah digunakan, maka dapat disimpulkan hasil dari dua ahli. Dari ahli akademisi BK insntrumen memiliki nilai indesk 0,34 dengan kriteria cukup baik/ cukup layak. Dari ahli praktisi BK instrumen memiliki nilai indeks 0,36 dengan kriteria cukup baik/ cukup layak. Hal ini memiliki arti bahwa, instrumen penilai kompetensi komunikasi dan interaksi positif konselor terhadap masyarakat sekolah dapat dilancarkan kepada konselor sekolah sebagai instrumen evaluasi kinerja dalam berkomunikasi dan berinteraksi positif dengan masyarakat sekolah.

Berdasarkan penelitian yang telah dilakukan maka didapat saran bagi peneliti selanjutnya agar (1) sebelum menerapkan instrumen, peneliti perlu memberikan pemahaman berupa penjelasan langsung terhadap guru BK akan fungsi dari instrumen evaluasi kinerja BK, (2) peneliti hendaknya dalam pengembangan instrumen menggunakan bahasa yang mudah dipahami, kalimat yang lugas dan sederhana, dan kalimat tidak terlalu panjang, (3) dalam penelitian selanjutnya perlu mengebangkan lebih lanjut hasil pengembangan dari penelitian ini dalam bentuk teknologi yang aplikatif, misalnya dalam bentuk web atau aplikasi android.

\section{DAFTAR RUJUKAN}

Astramovich, R. L., \& Coker, J. K. (2007). Program evaluation: The accountability bridge model for counselors. Journal of Counseling \& Development, 85(2), 162-172. https://doi.org/10.1002/j.1556-6678.2007.tb00459.x

Barida, Muya \& Sutamo, S. (2016). Pengembangan Instrumen Evaluasi "Self Evaluaation" dan "Peer Evaluation" Layanan Konseling Individual di Sekolah Bagi Konselor. Jurnal Konseling dan Pendidikan, 4(2), 110-117. https://doi.org/10.29210/17200

Coleman, H.L.K. \& Yeh, C. (2008) Handbook of School Counseling. New York: Routledge, Taylor \& Francis Group.

Daniel L. Stufflebeam, Chris L. S. Coryn. (2014). Evaluation Theory, Models, and Applications, ed.2nd. San Francisco: Jossey-Bass.

Febriani, Rahmi D. \& Triyono (2018). Faktor Penghambat Pelaksanaan Evaluasi Program Bimbingan dan Konseling oleh Guru Bimbingan dan Konseling. Jurnal Counseling Care, 2(1), 21-27. https://doi.org/10.22202/jcc.2018.v2i1.2860

Gibson, R.L., \& Mitchell. M.H. (2011). Bimbingan dan Konseling. Yogyakarta: Pustaka Pelajar.

Gregory, R.J. (2014). Psychological Testing: History, principle, and Application (7thed). Boston: Pearson.

Gysbers, N.C. \& Henderson, P. (2006). Developing \& Managing Your School Guidance and Counseling Program (7thed). Alexandria: American Counseling Assosiation.

Gysbers, N.C. \& Henderson, P. (2012) Developing \& managing your school guidance \& counseling program (5thed). Alexandria: American Counseling Association.

Hanggara, G.S. \& Setyaputri, N.Y. (2017) Kontribusi Kemenarikan Interpersonal Konselor pada Motivasi Siswa dalam Mengikuti Bimbingan Kelompok di Kota Malang. PSIKOPEDAGOGIA Jurnal Bimbingan dan Konseling, 6(1), 36-44. http://dx.doi.org/10.12928/psikopedagogia.v6i1.7122 
Hanggara, G., Andrianie, S., \& Ariyanto, R. (2018). Pengembangan Aplikasi Assessment Menggunakan Media Short Message Service. Jurnal Kajian Bimbingan dan Konseling, 3(4), 146-153. https://doi.org/10.17977/um001v3i32018p146

Hidayati S, N., Sugiyo, S., \& Wagimin, W. (2018). Pengembangan Model Instrumen Evaluasi Program Bimbingan dan Konseling Komprehensif di SMP Negeri Kota Samarinda. Jurnal Bimbingan Konseling, 6(2), 167-173. https://journal.unnes.ac.id/sju/index.php/jubk/article/view/21793

Juniarti, E., Endang, B., \& Lestari, S. (2017). Analisis Evaluasi Pelaksanaan Program Bimbingan Dan Konseling Bidang Sosial di SMA Negeri 9 Pontianak. Jurnal Pendidikan dan Pembelajaran Khatulistiwa, 7(7), 1-9. http://jurnal.untan.ac.id/index.php/jpdpb/article/view/26257

Linden, J.D., Stone, S.C. and Shertzer, B. (1965), Development and Evaluation of an Inventory for Rating Counseling. The Personnel and Guidance Journal, 44: 267-276. https://doi.org/10.1002/j.2164-4918.1965.tb03516.x

Mendiknas. (2008). Peraturan Menteri Pendidikan Nasional Republik Indonesia No. 27 Tahun 2008 tentang Standar kualifikasi dan Kompetensi Konselor. Kementerian Pendidikan Nasional Rl. $\quad$ https://bsnp-indonesia.org/id/wpcontent/uploads/tenaga/Permen_27_Th-2008.pdf

Missouri Departement of Elementary and Secondary Education. (2000). Guidelines for Performance-Based Profesional School Counselor Evaluation. Jefferson City, MO: Author.

Purwaningrum, Ribut. 2011. Pengembangan Instrumen Evaluasi Diri Penguasaan Teknik Dasar Komunikasi dalam Konseling pada Mahasiswa Program Studi Bimbingan dan Konseling Universitas Negeri Malang. Skripsi, Jurusan Bimbingan Konseling dan Psikologi, Fakultas IImu Pendidikan, Universitas Negeri Malang.

Schmith, J.J. (2008) Counseling in Schools: Comprehensive Program of Responsive Service for All Students (5thed). Boston: Pearson Education, Inc.

Sink, C. A. (2009). School counselors as accountability leaders: Another call for action. Professional School Counseling, 13(2), 68-74. https://doi.org/10.5330/PSC.n.2010$\underline{13.68}$

Sugiyo, Muslikah. (2018). Evaluation Models of Guidance and Counseling Service Based CIPP in Senior High School. Windiarti, R (Eds), Proceedings of the 4th International Conference on Early Childhood Education. Semarang Early Childhood Research and Education Talks (SECRET 2018) (pp. 242-249). Atlantis Press. https://doi.org/10.2991/secret-18.2018.41 